\title{
AIDS in Intensive Care Unit Patients: Epidemiology and Outcomes
}

Alessandro Kenji Yassue ${ }^{1}$, Camila Artuzi Oliveira' ${ }^{1}$, Claudia Santos Oliveira ${ }^{1}$, Luana Tossolini Goulart ${ }^{1}, K^{2}$ arina H Oikawa ${ }^{2}$, Amaury C Jorge ${ }^{2}$, Carla Sakuma Oliveira ${ }^{2}$ and Péricles AD Duarte ${ }^{2}$

${ }^{1}$ Universidade Estadual do Oeste do Paraná-Cascavel/PR, Brazil

${ }^{2}$ Hospital Universitário do Oeste do Paraná-Cascavel/PR, Brazil

\begin{abstract}
Background: Admission rates to intensive care unit (ICU) remains high in AIDS patients, although data in lowincome countries are scarce. The aim of this study was to evaluate the epidemiology, morbidity and mortality risk factors of HIVIAIDS patients admitted to the ICU of a university hospital in southern Brazil.
\end{abstract}

Methods: Retrospective cohort study with all patients aged >18 years in the ICU from 2004 to 2014 with a diagnosis of HIVIAIDS (previous or newly diagnosed).

Results: $1.7 \%$ of ICU patients had HIVIAIDS; of these, $67.1 \%$ were male, with an average of 40 years. $91.8 \%$ of hospitalizations were due to medical causes, and most patients (83.6\%) had no comorbidities. Mean APACHE 25.1, 95.1\% required invasive mechanical ventilation (MV), ICU stay 13.9 days, mortality $51.4 \%$. Among AIDS patients, incidence of complications was high: $41.7 \%$ acute respiratory distress syndrome (ARDS), $45.8 \%$ acute renal failure (ARF), $37.5 \%$ pneumonia. Approximately $1 / 3$ had diagnosis during hospitalization and $27.5 \%$ were on antiretroviral therapy. Mortality has progressively reduced over the years.

Conclusion: The prevalence of HIVIAIDS was $1.7 \%$. This group had a high incidence of complications, which were related to higher mortality. The mortality of this group has decreased in recent years in this population.

\section{Keywords: Intensive care unit; AIDS; Mortality; Epidemiology}

Abbreviations: AIDS: Acquired Immunodeficiency Syndrome; HAART: Highly Active Antiretroviral Syndrome Therapy; APACHE: Acute Physiology and Chronic Health Evaluation score; HIV: Human Immunodeficiency Virus; ARDS: Acute Respiratory Distress Syndrome; ICU: Intensive Care Unit; ARF: Acute Renal Failure; MD: Mechanical Ventilation; ART: Anti-RETROVIRAL THERAPY; $\mathrm{PaO}_{2}$ : Pressure of Arterial Oxygen; $\mathrm{CD}_{4}$ : Cluster of Differentiation 4 Lymphocytes; PEEP: Positive End-Expiratory Pressure; CHF: Congestive Heart Failure; PO: Post-Operative; COPD: Chronic Obstructive Pulmonary Disease; Rtx: Radiotherapy; CRF: Chronic Renal Failure; SAPS: Simplified Acute Physiology Score; Ctx: Chemotherapy; SD: Standard Deviation; DM: Diabetes Mellitus; $\mathrm{SH}$ : Systemic Hypertension; $\mathrm{FiO}_{2}$ : Fraction of Inspired Oxygen; SOFA: Score of Failure Organ

\section{Introduction}

According to the United Nations, in 2015 about 36.7 million people were living with the human immunodeficiency virus (HIV) in the world, with only about $43 \%$ having access to treatment. In Brazil, a prevalence of 0.4 to $0.8 \%$ of the population is estimated, with about 830,000 people living with acquired immunodeficiency syndrome (AIDS) [1]. Although the number of new cases in the world remains stable (around 2 million a year), the complexity of the epidemiological, social and clinical conditions involved makes the epidemic central to the concerns of international health authorities [2]. The costs related to the disease are astronomical: in the United States, it is estimated that treatment of infected persons could cost about 450 billion in health care per year $[3,4]$. Obviously, these costs do not measure the impressive social impact of the disease, which in low-income countries has reached a level of national tragedy [1].

Due to significant advances in the treatment of patients with AIDS (the "HAART [Highly active antiretroviral therapy] era"); the hospitalization of patients infected with HIV has reduced significantly in recent years, although not hospitalizations in intensive care unit
(ICU) [5]. Among the factors that justify this paradox are the increase in hospitalization for causes not related directly to AIDS (as postoperative), 'general' diseases but that increase in frequency late in the HIV patient (e.g. coronary atherosclerosis), and a change in the assistance paradigm and prognostic definition of this group of patients (increasing the chance of being transferred to the ICU) [5,6].

In Brazil, the incidence of new AIDS cases is stable at about 39,000 new cases a year, with mortality of 5.6/100,000 inhabitants/ year (although it reaches 8.5 in the current study). In public hospitals approximately 33,000 patients are hospitalized per year, with expenditures of at least $\$ 43$ million a year $[7,8]$.

The objective of the present study was to evaluate the prevalence, epidemiological/demographic aspects and morbidity and mortality risk factors in HIV/AIDS patients admitted to a general ICU of a public teaching hospital in southern Brazil.

\section{Methods}

In this cohort study, data were obtained retrospectively from the medical records of all patients hospitalized in the adult ICU of the Hospital Universitário do Oeste do Paraná (a public hospital with 173 beds), in Cascavel (southern Brazil) between 2004 and 2014, with a diagnosis of AIDS or HIV positive (previous or diagnosed in this

*Corresponding author: Pericles AD Duarte, General ICU-Hospital Universitário do Oeste do Paraná, Av. Tancredo Neves, 3224 - Santa Cruz, Cascavel - PR 85806-470, Brazil; Tel: +55-45-3321-5171; E-mail: pericles.duarte@unioeste.br; pericles.duarte@uol.com.br

Received April 27, 2017; Accepted May 12, 2017; Published May 19, 2017

Citation: Yassue AK, Oliveira CA, Oliveira CS, Goulart LT, Oikawa KH, et al. (2017) AIDS in Intensive Care Unit Patients: Epidemiology and Outcomes. J AIDS Clin Res 8: 691. doi: 10.4172/2155-6113.1000691

Copyright: (c) 2017 Yassue AK, et al. This is an open-access article distributed under the terms of the Creative Commons Attribution License, which permits unrestricted use, distribution, and reproduction in any medium, provided the original author and source are credited. 
hospital stay) and compared with non-AIDS patients. A more detailed spreadsheet was generated over a period of 2 years (2013-2014), only for patients with AIDS. The reason for not including HIV-AIDS patients from previous years (2004-2012) was the impossibility of obtaining their full data. Thus, the sample size was chosen by convenience.

The exclusion criterion was patients admitted to the ICU who were under 18 years of age. The data were compared with a general database of the adult ICU (with patients tabulated since 2004).

As a definition of mortality, it was considered ICU or hospital mortality.

\section{Criteria}

-Acute Renal Failure (ARF): Any serum creatinine $\geq 1.50 \mathrm{mg} / \mathrm{dl}$, excluding patients with known prior renal disease;

-Thrombocytopenia: Any platelet count $<100,000$ cells $/ \mathrm{mm}^{3}$;

-Use of vasoactive drugs: Any dose of noradrenaline, dopamine or vasopressin;

-Comorbidities (e.g. Chronic Obstructive Pulmonary Disease [COPD], Chronic Heart Failure [CHF], Chronic Renal Disease [CRD]): clinically defined by the care team;

-Acute Respiratory Distress Syndrome (ARDS): According to the criteria of the European-American Consensus [9], in force at the time of patient management;

-Hepatitis: Total transaminase elevation (alanine+aspartate) above 5 times the reference value.

The data were tabulated in the Excel program. Descriptive statistical analysis was performed and percentages expressed as frequency, mean and standard deviation.

The quantitative variables were evaluated by Mann-Whitney-U test. For the qualitative variables, the Chi-square test for independence was performed, and in cases of not reaching the minimum expected frequency assumption equal to 1 , the Chi-square test for Independence was applied with the Monte Carlo permutation method. For the univariate statistical analysis, a significance level of 0.05 was used.

Binary logistic regression was performed to find factors related to mortality in HIV/AIDS patients. It was made selection of the predictor variables of the model using the odds ratio criterion that $\mathrm{P}<0.10$ was statistically equivalent to 1 . A model was obtained with a reduced number of variables, selected from the application of the criterion that $\mathrm{P}<0.05$ of the adjusted odds ratio was statistically equivalent to 1 . A final model was then achieved after testing for all possible multiple iterations, by using the maximization of the Wald function. Hosmer and Lemeshow statistic was used to verify the fit of the models. Once the final logistic regression model was decided, for each of the mentioned objectives, the probabilities were calculated from the formula $\mathrm{Pr}=1$ / $[1+\mathrm{e}-(\alpha+\Sigma(\beta \mathrm{ixi})]$, where $\alpha$ is the constant of the model.

The study was conducted in accordance with the recommendations in Resolution 466/2012 of the Brazilian National Council of Health. This study was approved by the Research Ethics Committee of the Universidade Estadual do Oeste do Paraná-UNIOESTE.

\section{Results}

During the study period (July 2004 to December 2014), 4188 patients were admitted to the ICU. Of these 73 (1.74\%) had HIV/AIDS and were included in the study. Among the patients with AIDS, $67.12 \%$ were male and 40 years old. Almost all (91.78\%) hospitalizations of patients with AIDS were due to medical causes. Most of the patients (83.6\%) had no previous diseases. They were very serious patients: the mean Acute Physiology and Chronic Health Evaluation (APACHE) of admission was $25.1 ; 95.08 \%$ required invasive mechanical ventilation (MV), the mean ICU stay was 13.9 days and ICU mortality was $51.35 \%$. Table 1 shows the clinical-demographic characteristics of patients with AIDS and non-AIDS in this period.

Figure 1 shows the evolution of the prevalence and mortality of patients with AIDS in the ICU in 2004-2014, with a progressive reduction in mortality, particularly in the last period.

When only patients with AIDS were evaluated (years 2013-2014), the incidence of complications was high: $41.7 \%$ presented ARDS, $45.8 \%$ ARF (although only $4.2 \%$ required dialysis), $43.8 \%$ thrombocytopenia, $37.5 \%$ nosocomial pneumonia and $20.8 \%$ hepatitis. Approximately $1 / 3$ of the patients were diagnosed with AIDS during the current hospitalization and $37.5 \%$ were using antiretrovirals. However, perhaps due to reduced ' $n$ ', only the presence of ARDS and/or ARF was associated with higher ICU mortality (Table 2).

Among HIV/AIDS patients $(n=24)$, the variables considered significant (risk of death) by the logistic regression method were: cause of hospitalization (neurological and emergency surgery), admission APACHE II and MV length of time (Table 3).

\section{Discussion}

Despite the reduction in hospital admissions of patients with AIDS due to improved treatment, admissions in ICU of AIDS patients remain high [10]. In 2 years period, up to $33 \%$ of AIDS patients require hospitalization; of these, $17.8 \%$ need admission to the ICU [6]. In national studies, the incidence of AIDS patients in the general ICU population varies between $0.16 \%$ (Holland) [11] and 2.6\% (France) [12]. In the current study, the prevalence of HIV/AIDS patients in the total ICU population was $1.7 \%$.

In our population, most (67\%) were male and the mean age was 40.6 years. Despite the increased incidence of women with AIDS in recent years [1], there is in general a clear predominance of male gender among AIDS patients admitted to the ICU, and this trend has not changed over the years [13-15]. There has been a clear change in the profile of patients, with increasing age $[12,15]$ and, consequently, the frequency of comorbidities among these patients admitted to the ICU.

The population of our study was severely ill: APACHE II admission was significantly higher in AIDS patients compared with the non-AIDS group. Despite a higher score in patients who died, we did not find statistically significant differences of APACHE II as a predictor of mortality. The authors believe that this was due only to the insufficient number of patients to detect this difference. However, the literature is controversial about severity scores (APACHE, SOFA and SAPS) in AIDS patients compared with non-AIDS patients in ICUs $[6,13,16-20]$.

In the current study, AIDS patients had a lower frequency of comorbidities than non-AIDS patients. The incidence of smoking, alcohol consumption and use of illicit drugs was slightly higher, although with no statistical difference.

Since the introduction of antiretroviral therapy, the mortality attributed to opportunistic infections associated with AIDS has decreased significantly with a proportional increase in HIV-infected patients who are living with viral replication control and preserved immune function. Increased survival translates into an ageing 
Citation: Yassue AK, Oliveira CA, Oliveira CS, Goulart LT, Oikawa KH, et al. (2017) AIDS in Intensive Care Unit Patients: Epidemiology and Outcomes. J AIDS Clin Res 8: 691. doi: 10.4172/2155-6113.1000691

Page 3 of 7

\begin{tabular}{|c|c|c|c|c|}
\hline & Total ICU n=4188 & AIDS $n=73$ & Non-AIDS $n=4115$ & $\mathbf{p}$ \\
\hline Male gender, $\mathbf{n}(\%)$ & $2607(62.24 \%)$ & $49(67.12 \%)$ & $2558(62.16 \%)$ & 0.456 \\
\hline Age, years & $48(31-64)$ & $40(34-47)$ & $48(31-64.75)$ & $-\cdots$ \\
\hline Comorbidity non-AIDS, n (\%) & $-\ldots \ldots$ & $-\ldots \ldots$ & $-\ldots-\ldots$ & --- \\
\hline No (none) & $1710(40.8 \%)$ & $61(83.6 \%)$ & $1649(40.1 \%)$ & $<0.001$ \\
\hline SH & $985(23.52 \%)$ & $2(2.74 \%)$ & $983(23.89 \%)$ & $<0.001$ \\
\hline DM & $293(7.00 \%)$ & $1(1.37 \%)$ & $292(7.09 \%)$ & 0.095 \\
\hline Obesity & $126(3.01 \%)$ & 0 & $126(3.06 \%)$ & 0.241 \\
\hline COPD & $234(5.59 \%)$ & $1(1.37 \%)$ & $233(5.66 \%)$ & 0.185 \\
\hline Heart Failure & $217(5.18 \%)$ & 0 & $217(5.27 \%)$ & 0.080 \\
\hline Chronic Renal Disease & $83(1.98 \%)$ & $1(1.37 \%)$ & $82(1.99 \%)$ & 0.963 \\
\hline Liver disease/cirrhosis & $59(1.41 \%)$ & $3(4.11 \%)$ & $56(1.36 \%)$ & 0.140 \\
\hline Cancer & $277(6.61 \%)$ & 0 & $277(6.73 \%)$ & 0.040 \\
\hline Ctx (last 2 months) & $1(0.02 \%)$ & 0 & $1(0.02 \%)$ & 0.107 \\
\hline Rtx (last 2 months) & $1(0.02 \%)$ & 0 & $1(0.02 \%)$ & 0.107 \\
\hline Others & $635(15.16 \%)$ & $4(5.48 \%)$ & $558(13.56 \%)$ & 0.067 \\
\hline Habits, n (\%) & - - - - - - & $-\ldots-\ldots$ & $-\ldots-\ldots$ & --- \\
\hline Smoking & $227(5.42 \%)$ & $8(10.96 \%)$ & $219(5.32 \%)$ & 0.064 \\
\hline Alcoholism & $262(6.25 \%)$ & $7(9.59 \%)$ & $255(6.20 \%)$ & 0.346 \\
\hline Illicit drugs & $57(1.36 \%)$ & $3(4.11 \%)$ & $54(1.31 \%)$ & 0.124 \\
\hline Cause of ICU admission, $\mathrm{n}(\%)$ & $\ldots \ldots$ & $\ldots \ldots$ & $-\ldots-\ldots$ & $-\cdots$ \\
\hline Trauma & $1248(30.50 \%)$ & $2(2.74 \%)$ & $1246(31.01 \%)$ & \multirow{4}{*}{$<0.001$} \\
\hline PO Elective surgery & $644(15.73 \%)$ & $1(1.37 \%)$ & $643(16.00 \%)$ & \\
\hline $\begin{array}{l}\text { PO non-trauma emergency } \\
\text { surgery }\end{array}$ & $524(12.80 \%)$ & $3(4.11 \%)$ & $519(12.92 \%)$ & \\
\hline $\begin{array}{l}\text { Medical (includes } \\
\text { obstetrics) }\end{array}$ & $1677(40.97 \%)$ & $67(91.78 \%)$ & $1610(40.07 \%)$ & \\
\hline APACHE II & $21(14-27)$ & $24(19-29.75)$ & $21(14-27)$ & $<0.01$ \\
\hline Invasive VM, days & $3(1-9)$ & $5.5(2-13.5)$ & $3(1-9)$ & 0.027 \\
\hline Invasive MV, days, n (\%) & $-\ldots-\ldots$ & $-\ldots-\ldots$ & $-\ldots-\ldots$ & --- \\
\hline 0 & $850(20.30 \%)$ & $4(5.00 \%)$ & $872(21.20 \%)$ & \multirow{5}{*}{0.001} \\
\hline $1-2$ & $1035(24.70 \%)$ & $16(21.6 \%)$ & $1010(24.55 \%)$ & \\
\hline $3-5$ & $712(17.00 \%)$ & $17(23.30 \%)$ & $689(16.74 \%)$ & \\
\hline $6-10$ & $670(16.00 \%)$ & $12(16.70 \%)$ & $652(15.85 \%)$ & \\
\hline$>10$ & $921(22.00 \%)$ & $24(33.40 \%)$ & $892(21.66 \%)$ & \\
\hline ICU length of stay, days & $5.5(3-13)$ & $8(4-19)$ & $5(3-12)$ & 0.015 \\
\hline Hospital length of stay, days & $19(11-32)$ & $36.5(19.25-57.75)$ & $19(11-31)$ & $<0.01$ \\
\hline ICU mortality, n (\%) & $1208(28.84 \%)$ & $37(51.35 \%)$ & $1044(25.38 \%)$ & $<0.001$ \\
\hline Hospital mortality, n (\%) & $1848(44.14 \%)$ & $47(64.61 \%)$ & $1365(33.17 \%)$ & $<0.001$ \\
\hline
\end{tabular}

ICU: Intensive Care Unit; SD: Standard deviation; SH: Systemic Hypertension; DM: Diabetes Mellitus; COPD: Chronic Obstructive Pulmonary Disease; Ctx: Chemotherapy; Rtx: Radiotherapy; PO: Post-operative; APACHE: Acute Physiology and Chronic Health Evaluation; MV: Mechanical Ventilation

The data of quantitative variables are expressed as median ( $1^{\text {st }}$ quartile- $3^{\text {rd }}$ quartile)

Table 1: Baseline characteristics and outcomes of ICU patients with AIDS compared with non-AIDS patients (Patients 2004-2014).

population with increased chronic diseases such as hepatitis $\mathrm{C}$ and hepatic cirrhosis, cardiovascular diseases (e.g. atherosclerotic diseases), renal insufficiency, lung diseases (COPD) and neoplasms [12,21]. The high incidence of hepatic diseases (by association with alcoholism, hepatotoxicities or hepatitis $\mathrm{B}$ and $\mathrm{C}$ ) becomes an important comorbidity with its consequences, such as spontaneous bacterial peritonitis, digestive haemorrhage or hepatic encephalopathy. The same happens with the association of smoking and potentiation of respiratory or cardiovascular risk [14,22].

Despite evidence of greater alcohol use [23], smoking [24] and illicit drug use [25] in patients with AIDS and the potentiation of these factors in the morbidity and mortality of the disease, few studies have evaluated the extent of these habits in hospitalized patients in ICU. In elderly male AIDS patients, the incidence of smoking and alcohol consumption was higher among patients requiring hospitalization, although among inpatients there were no differences with those requiring ICU admission [6].
In the population of our study, the most common cause of admission was due to clinical diseases. Despite the improvement in the treatment of patients with AIDS and a consequent increase in quality of life and life span, most hospitalizations of AIDS patients continue to be due to clinical conditions [12-14,17-19], although increasingly by conditions not necessarily related to AIDS (such as coronary disease, cirrhosis, COPD and neoplasms) [6]. On the other hand, admissions due to elective surgeries have increased by up to $100 \%$ in recent years in this population [12], evidence of a change in the approach and prognosis paradigm of the disease.

The incidence of complications among AIDS patients was high in the current study: $41.7 \%$ had ARDS, $45.8 \%$ ARF (although only $4.2 \%$ needed dialysis), $43.8 \%$ had thrombocytopenia, $37.5 \%$ nosocomial pneumonia and $20.8 \%$ hepatitis. In patients with AIDS, the incidence of complications was obviously higher in patients who died. Respiratory (ARDS) and renal (ARF) were the most complications associated with the risk of death. 
Citation: Yassue AK, Oliveira CA, Oliveira CS, Goulart LT, Oikawa KH, et al. (2017) AIDS in Intensive Care Unit Patients: Epidemiology and Outcomes. J AIDS Clin Res 8: 691. doi: 10.4172/2155-6113.1000691

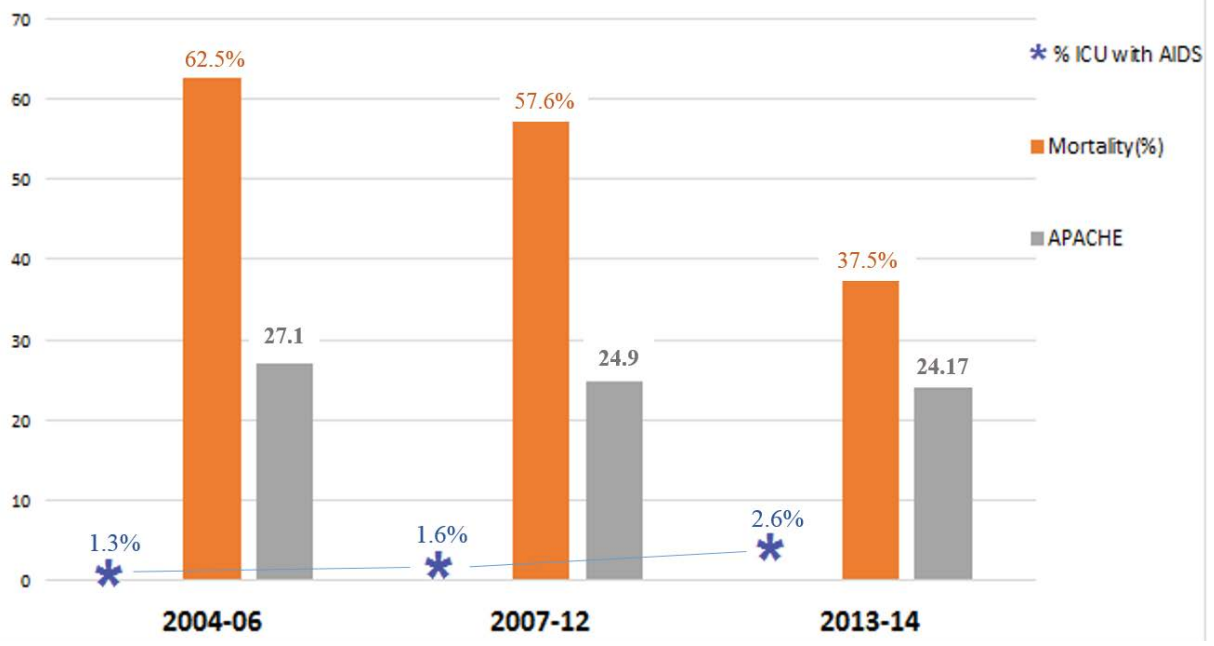

Figure 1: Prevalence and mortality of patients with AIDS in ICU, in period 2004-2014.

\begin{tabular}{|c|c|c|c|c|}
\hline & Total AIDS $n=24$ & Alive $n=15$ & Death ICU $n=9$ & p \\
\hline Male gender, $\mathbf{n}(\%)$ & $14(58.33 \%)$ & $10(66.67 \%)$ & $4(44 \%)$ & - \\
\hline Age, years & $43(34-46.25)$ & $45(35-46.5)$ & $39(30-45)$ & 0.982 \\
\hline Comorbidities, n (\%) & $-\ldots$ & $-\ldots$ & $-\ldots$ & $-\ldots$ \\
\hline No (none) & $14(58.3 \%)$ & $7(46.7 \%)$ & $7(77.8 \%)$ & \multirow{7}{*}{0.479} \\
\hline SH & $5(20.83 \%)$ & $4(26.66 \%)$ & $1(11.11 \%)$ & \\
\hline DM & $2(8.33 \%)$ & $2(13.3 \%)$ & 0 & \\
\hline Obesity & 0 & 0 & 0 & \\
\hline COPD & $2(8.33 \%)$ & $2(13.33 \%)$ & 0 & \\
\hline Liver disease/cirrhosis & $2(8.33 \%)$ & $2(13.33 \%)$ & 0 & \\
\hline Others & $4(16.66 \%)$ & $2(13.33 \%)$ & $2(22.22 \%)$ & \\
\hline Habits, n (\%) & $-\ldots$ & $-\ldots$ & $-\ldots$ & $-\ldots$ \\
\hline Smoking & $12(50 \%)$ & $8(53.33 \%)$ & $4(44.44 \%)$ & 1.000 \\
\hline Alcoholism & $10(41.66 \%)$ & $7(46.66 \%)$ & $3(33.33 \%)$ & 0.831 \\
\hline Illicit drugs & $4(16.66 \%)$ & $3(20 \%)$ & $1(11.11 \%)$ & 1.000 \\
\hline Cause of ICU admission, $\mathrm{n}(\%)$ & $\ldots \ldots$ & $-\ldots \ldots$ & $-\ldots \ldots$ & \multirow{5}{*}{0.561} \\
\hline Trauma & $1(4.17 \%)$ & $1(6.67)$ & 0 & \\
\hline PO elective surgery & 0 & 0 & 0 & \\
\hline PO non-trauma emergence surgery & $2(8.33 \%)$ & $2(13.33 \%)$ & 0 & \\
\hline Medical (includes obstetrics) & $21(87.5 \%)$ & $12(80 \%)$ & $9(100 \%)$ & \\
\hline APACHE II & $24.5(19.5-28)$ & $24(18.5-27.5)$ & $27(22-28)$ & 0.348 \\
\hline $\begin{array}{l}\text { Was the diagnosis of AIDS made before } \\
\text { hospitalization? Yes, } n(\%)\end{array}$ & $16(66.7 \%)$ & $10(66.7 \%)$ & $6(66.7 \%)$ & 0.655 \\
\hline $\begin{array}{l}\text { Time of AIDS diagnosis before hospitalization } \\
\text { (months), } n(\%)\end{array}$ & $-\ldots$ & $-\ldots$ & $-\ldots$ & 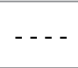 \\
\hline 0 (Diagnosis in this admission) & $8(33.3 \%)$ & $5(33.3 \%)$ & $3(33.3 \%)$ & \multirow{5}{*}{0.672} \\
\hline $1-2$ & $5(8.33 \%)$ & $2(13.3)$ & $3(33.3 \%)$ & \\
\hline 3-6 & $1(4.16 \%)$ & $1(6.7 \%)$ & 0 & \\
\hline $7-12$ & $1(4.16 \%)$ & $1(6.7 \%)$ & 0 & \\
\hline$>12$ & $9(37.5 \%)$ & $6(40.0 \%)$ & $3(33.3 \%)$ & \\
\hline Previous ART n (\%) & $9(37.5 \%)$ & $6(40.0 \%)$ & $3(33.3 \%)$ & 0.915 \\
\hline $\begin{array}{l}\text { Last CD4 before hospitalization, cells } / \mathrm{mm}^{3} \text {, } \\
\text { mean } \pm \text { SD }\end{array}$ & $333.0 \pm 316.43$ & $328.0 \pm 334.7$ & $339.6 \pm 363.0$ & 0.937 \\
\hline Invasive VM, days & $7(4-12.5)$ & $5(3.5-11)$ & $8(6-13)$ & 0.067 \\
\hline Invasive VM, days, n (\%) & $-\ldots-\ldots$ & $-\ldots \ldots$ & $-\ldots-\ldots$ & $-\ldots$ \\
\hline 0 & $1(4.17 \%)$ & $1(6.67 \%)$ & 0 & \multirow{5}{*}{0.274} \\
\hline $1-2$ & $2(8.33 \%)$ & $1(6.67 \%)$ & $1(11.11 \%)$ & \\
\hline $3-5$ & $8(33.33 \%)$ & $7(46.66 \%)$ & $1(11.11 \%)$ & \\
\hline $6-10$ & $6(25 \%)$ & $2(13.33 \%)$ & $4(44.45 \%)$ & \\
\hline$>10$ & $7(29.17 \%)$ & $4(26.67 \%)$ & $3(33.33 \%)$ & \\
\hline
\end{tabular}


Citation: Yassue AK, Oliveira CA, Oliveira CS, Goulart LT, Oikawa KH, et al. (2017) AIDS in Intensive Care Unit Patients: Epidemiology and Outcomes. J AIDS Clin Res 8: 691. doi: 10.4172/2155-6113.1000691

Page 5 of 7

\begin{tabular}{|c|c|c|c|c|}
\hline ARDS, n (\%) & $10(41.66 \%)$ & $4(26.67 \%)$ & $6(66.67 \%)$ & 0.134 \\
\hline Lowest $\mathrm{PaO}_{2} / \mathrm{FiO}_{2}$, mean $\pm \mathrm{SD}$ & $165.9 \pm 80.07$ & $190.1 \pm 89.01$ & $125.6 \pm 40.53$ & 0.054 \\
\hline Lowest $\mathrm{PaO}_{2} / \mathrm{FiO}_{2}, \mathrm{n}(\%)$ & - - - - - & $\ldots \ldots$ & - - - - - & $-\cdots$ \\
\hline$<100$ & $4(16.66 \%)$ & $1(6.66 \%)$ & $3(33.33 \%)$ & \multirow{4}{*}{0.088} \\
\hline $101-200$ & $14(58.34 \%)$ & $8(53.34 \%)$ & $6(66.67 \%)$ & \\
\hline 201-300 & $4(16.66 \%)$ & $4(26.67 \%)$ & 0 & \\
\hline$>300$ & $2(8.34 \%)$ & $2(13.33 \%)$ & 0 & \\
\hline Highest PEEP, mean \pm SD & $7.4 \pm 3.40$ & $6.6 \pm 1.59$ & $9.8 \pm 4.57$ & 0.023 \\
\hline Highest PEEP, n (\%) & $\ldots$ & $-\ldots$ & $\ldots \ldots$ & $-\cdots$ \\
\hline $0-4$ & 0 & 0 & 0 & \\
\hline $5-9$ & $18(78.26 \%)$ & $13(92.85 \%)$ & $5(55.55 \%)$ & \multirow{3}{*}{0.099} \\
\hline $10-14$ & $3(13.05 \%)$ & $1(7.14 \%)$ & $2(22.22 \%)$ & \\
\hline$>14$ & $2(8.69 \%)$ & 0 & $2(22.22 \%)$ & \\
\hline ARF, n (\%) & $11(45.83 \%)$ & $4(26.66 \%)$ & $7(77.77 \%)$ & 0.044 \\
\hline Highest serum creatinine, mg/dl, mean \pm SD & $2.1 \pm 1.65$ & $2.3 \pm 1.88$ & $1.8 \pm 1.22$ & 0.503 \\
\hline Highest blood urea, mg/dl, mean \pm SD & $95.0 \pm 86.66$ & $68.9 \pm 36.21$ & $110.7 \pm 104.33$ & 0.166 \\
\hline Dialysis need, n (\%) & $1(4.16 \%)$ & 0 & $1(4.16 \%)$ & 0.365 \\
\hline Leukocytes<4500/mm³ $\mathrm{n}(\%)$ & $13(54.16 \%)$ & $9(60 \%)$ & $4(44.44 \%)$ & 0.751 \\
\hline Thrombocytopenia, n (\%) & $10(43.83 \%)$ & $5(33.33 \%)$ & $5(66.66 \%)$ & 0.245 \\
\hline Pneumonia in the ICU, $n$ (\%) & $9(37.5 \%)$ & $5(33.33 \%)$ & $4(44.44 \%)$ & 0.913 \\
\hline Hepatitis, $\mathbf{n}(\%)$ & $5(20.8 \%)$ & $3(20.0 \%)$ & $2(22.2 \%)$ & 0.696 \\
\hline ICU length of stay, days & $9.5(7.75-15.5)$ & $11(8-13.5)$ & $9(7-29)$ & 0,0294 \\
\hline ICU length of stay (days), $n$ (\%) & $-\ldots$ & $-\ldots$ & $-\ldots-\ldots$ & $-\cdots$ \\
\hline 1 & $1(4.16 \%)$ & $1(6.67 \%)$ & 0 & \multirow{4}{*}{0.399} \\
\hline $2-5$ & $3(12.5 \%)$ & $1(6.67 \%)$ & $2(22.22 \%)$ & \\
\hline $6-10$ & $9(37.5 \%)$ & $4(26.66 \%)$ & $5(44.45 \%)$ & \\
\hline$>10$ & $11(45.84 \%)$ & $9(60 \%)$ & $2(33.33 \%)$ & \\
\hline Hospital length of stay, days & $37(16-52)$ & $46(31-7.7)$ & $30(10-56)$ & $<0.05$ \\
\hline
\end{tabular}

ICU: Intensive Care Unit; SD: Standard Deviation; SH: Systemic Hypertension; DM: Diabetes Mellitus; COPD: Chronic Obstructive Pulmonary Disease; PO: Post-Operative; APACHE: Acute Physiology and Chronic Health Evaluation; MV: Mechanical Ventilation; ARDS: Acute Respiratory Distress Syndrome; PEEP: Positive End-Expiratory Pressure; ARF: Acute Renal Failure; ART: Antiretroviral Therapy

The data of quantitative variables are expressed as median ( $1^{\text {st }}$ quartile- $3^{\text {rd }}$ quartile)

Table 2: Baseline characteristics and outcomes of patients in ICU with AIDS, 2013-2014.

\begin{tabular}{|c|c|c|c|c|c|}
\hline Variable & Coefficient & Pr $>$ Qui $^{2}$ & OR & OR low (95\%) & OR upper (95\%) \\
\hline Intercept & -0.067 & 0.916 & & & \\
\hline Admission cause: Emergency Surgery & -3.109 & 0.175 & 0.045 & 0.000 & 4.011 \\
\hline Admission cause: Neurological & -1.144 & 0.300 & 0.318 & 0.037 & 2.778 \\
\hline APACHE & 0.037 & 0.495 & 1.038 & 0.932 & 1.156 \\
\hline MV length of time (days) & 0.095 & 0.164 & 1.100 & 0.962 & 1.257 \\
\hline
\end{tabular}

OR: Odds Ratio; OR low (95\%): Lower range limit with 95\% confidence; OR Upper (95\%): Upper range limit with 95\% confidence

Table 3: Parameters obtained for the model created through the application of logistic regression in HIVIAIDS patients in order to find the factors associated with mortality $(n=24)$.

A few studies have reported on the incidence of ARDS in AIDS patients admitted to ICU: one study described an incidence of $5.4 \%$ [26], although possibly underestimating its true incidence. On the other hand, the impact of ARDS on patients with AIDS, although with high mortality, does not seem to differ from the non-AIDS patients $[17,27]$. The high incidence of ARDS in our AIDS population could reflect factors related to the greater severity of the patients (due to the scarcity of ICU beds and the need to select only more critical patients) or factors related to suboptimal management of precipitating conditions of ARDS, such as sepsis and trauma.

We sought to evaluate the timing of the diagnosis of HIV/AIDS, and the number of patients diagnosed during hospital stay. In our sample, approximately one-third of the patients had AIDS diagnosed during the current hospitalization; $55 \%$ of those who already knew of the diagnosis were using antiretroviral therapy (ART) before admission. Despite improvements in care and management of AIDS patients, literature shows a disproportion about previous diagnosis among patients admitted to ICU with AIDS: whereas in high-income countries only $19-28 \%$ of patients had no previous diagnosis $[10,16,20]$, in poor or low-income countries this number reaches 47\% [14], making the discussion about whether or not to start ART in this newly diagnosed group in critical situation more frequent in these places [28].

ICU and hospital length of stay and mortality (ICU and hospital) were significantly higher in patients with AIDS. The main risk factor for mortality in HIV+ patients was, as already described, the severity of the acute disease (e.g. higher APACHE), neurological causes and the presence of clinical complications and MV length of time (Table 3). AIDS-related factors (such as presence of Kaposi's sarcoma, CD4 level and viral count, for example) are described in the literature as associated with higher hospital mortality $[6,14,22]$. However, as found in our population, most of the deaths are related to the severity of the current clinical condition and its complications, such as sepsis, respiratory failure/ARDS, ARF and organ dysfunction, similar to nonAIDS patients $[14,17,19,20,22,29]$. 
Despite the small number of patients in this study, we found that there is a progressive reduction in the mortality of AIDS patients in recent years in our ICU, even with high severity (perceived by the APACHE of little admission altered) (Figure 1). It is possible that this improvement is due to better training of the team in general; our database shows that overall ICU mortality has been falling in this period, even with the general patient severity; (APACHE score) relatively unchanged. However, factors related to the specific management of patients with AIDS may have contributed to this result. One is the change in philosophy of approaching the patient living with HIV from an initial near-nihilistic attitude towards a current aggressive strategy (considering now to deal with a chronic disease such as Diabetes Mellitus, COPD or CHF). In addition, the very cause of this change (the use of HAART) guaranteed by the Brazilian health system has allowed an undeniable change in the prognosis of this disease in the country. Finally, the indispensable intensivist infectious diseases specialist collaboration allows individualizing the management of these patients and their serious infectious complications, specific or not.

This study has some limitations, some of them intrinsic to its nature. Because it is a retrospective cohort, data reliability may be impaired by non-standardized data collection. Because it is a single centre, the number of patients and the local characteristics may not allow generalizations of the data the researchers found. For example, it is a public teaching hospital with a low-income population and a referral hospital with limited beds availability (therefore, the population assigned to the ICU will be more severe patients). The population of non-AIDS patients follows the specific characteristics of the hospital: few cancer patients and many patients with trauma (therefore with a lower average age). In addition, not all laboratory data relevant to AIDS are available at inpatient care (e.g. CD4 or viral load). In addition, patient management was based on the team's clinical decision, which impedes further evaluation of the impact of certain strategies (e.g. ventilatory or antibiotic management) on patient outcomes. However, the objective of this study was a 'real life' evaluation of a Brazilian public hospital, evaluating the epidemiological and clinical characteristics of these patients, and therefore this study was used to this end.

\section{Conclusion}

In this sample of patients in a general ICU in a university hospital in southern Brazil, the prevalence of HIV/AIDS was $1.7 \%$. This group had a high incidence of complications, which was related to higher mortality. Nevertheless, the mortality of this population has decreased in recent years.

\section{Ethical Approval and Consent to Participate}

This study was conducted in accordance with the recommendations of Resolution 466/2012 of the Brazilian National Health Council. The project was approved by the Research Ethics Committee of the Universidade Estadual do Oeste do Paraná-UNIOESTE. Accordingly, post-informed consent was waived, since this current study only describes the results of a population already previously treated.

\section{Statement of Patient Data Confidentiality}

The authors declare that they guarantee the confidentiality of patient data regarding the publication of this study.

\section{Author's Contributions}

PADD designed the study, analyze the data, wrote the manuscript; AKY, CAO, CSO, LTG, KHO collected the data, analyzed the data, wrote the manuscript. $\mathrm{KHO}, \mathrm{ACJ}, \mathrm{CSO}$ analyzed the data, wrote and reviewed the manuscript. All the authors read and approved the final manuscript.

\section{References}

1. World Health Association (2016) UNAIDS, Global AIDS Update 2016.

2. Frieden TR, Foti KE, Mermin J (2015) Applying public health principles to the HIV epidemic: How are we doing? N Engl J Med 373: 2281-2287.

3. Centers for Disease Control and Prevention (CDC) (2011) Vital signs: HIV prevention through care and treatment United States. MMWR Morb Mortal Wkly Rep 60: 1618-1623.

4. Castel AD, Magnus M, Greenberg AE (2015) Update on the epidemiology and prevention of HIVIAIDS in the United States. Curr Epidemiol Rep 2: 110-119.

5. Kar SK, Chakraborty B, Ghosh S, Sarkar M, Ray R (2015) HIV in intensive care unit: Concerns and constraints of intensivists. Trans Biomedicine 6: 28.

6. Akgun KM, Gordon K, Pisani M, Fried T, McGinnis KA, et al. (2013) Risk factors for hospitalization and medical intensive care unit (MICU) admission among HIV-infected veterans. J Acquir Immune Defic Syndr 62: 52-59.

7. http://www2.datasus.gov.br/DATASUS/

8. Ministério da Saúde - Brasil (2016) Secretaria de Vigilância em Saúde. Boletim Epidemiológico HIV-AIDS - ano V $n^{\circ} 1$. Ministério da Saúde/Brasil, Brasília (DF).

9. Bernard GR, Artigas A, Brigham KL, Carlet J, Falke K, et al. (1994) The American-European Consensus Conference on ARDS. Definitions mechanisms, relevant outcomes and clinical trial coordination. Am J Respir Crit Care Med 149: 818-824.

10. Vincent B, Timsit JF, Auburtin M, Schortgen F, Bouadma L, et al. (2004) Characteristics and outcomes of HIV-infected patients in the ICU: Impact of the highly active antiretroviral treatment era. Intens Care Med 30: 859-866.

11. Huson MA, Bakhshi-Raiez F, Grobusch MP, de Jonge E, de Keizer NF, et al. (2016) Characteristics and outcome of patients with AIDS in Dutch ICUs between 1997 and 2014. Crit Care Med 44: 291-299.

12. Barbier F, Roux A, Canet E, Martel-Samb P, Aegerter P, et al. (2014) Temporal trends in critical events complicating HIV infection: 1999-2010 multicentre cohort study in France. Intens Care Med 2014; 40: 1906-1915.

13. Greenberg JA, Lennox JL, Martin GS (2012) Outcomes for critically ill patients with HIV and severe sepsis in the era of highly active antiretroviral therapy. J Crit Care 27: 51-57.

14. Verdugo F, Pinto F, Charpentier P, Muhlenbrock CV, Soto A, et al. (2015) Pacientes con infección por VIH/SIDA em uma Unidad de Pacientes Críticos. La experiencia de un hospital general en un país en desarrollo. Rev Chil Infectol 32: 294-303.

15. Mary-Krause M, Grabar S, Lievre L, Abgrall S, Billaud E, et al. (2014) Cohort profile: French hospital database on HIV. Intern J Epidemiol 43: 1425-1436.

16. Cribbs SK, Tse C, Andrews J, Shenvi N, Martin GS (2015) Characteristics and outcomes of HIV-infected patients with severe sepsis: Continued risk in the post-highly active antiretroviral therapy era. Crit Care Med 43: 1638-1645.

17. Nirappil FJ, Maheshwari A, Andrews J, Martin GS, Esper AM, et al. (2015) Characteristics and outcomes of HIV-1 infected patients with acute respiratory distress syndrome. J Crit Care 30: 60-64.

18. Husstedt IW, Braicks O, Reichelt D, Oelker-Grueneberg U, Evers S (2013) Treatment of immigrants and residents suffering from neuro-aids on a neurological intensive care unit: Epidemiology and predictors of outcomes. Acta Neurol Belg 113: 391-395.

19. Amancio RT, Japiassu AM, Gomes RN, Mesquita EC, Assis EF, et al. (2013) The innate immune response in HIVIAIDS septic shock patients: A comparative study. PLOS ONE 8.

20. Meybeck A, Lecomte L, Valette M, Van Grunderbeeck N, Boussekey N, et al. (2012) Should highly active antirretroviral therapy be prescribed in critically ill HIV-infected patients during the ICU stay? A retrospective cohort study. AIDS Res Ther 9: 27.

21. Gingo MR, Morris A (2015) HIV infection and severe sepsis: A bitter pill to swallow. Crit Care Med 43: 1779-1780. 
Citation: Yassue AK, Oliveira CA, Oliveira CS, Goulart LT, Oikawa KH, et al. (2017) AIDS in Intensive Care Unit Patients: Epidemiology and Outcomes. J AIDS Clin Res 8: 691. doi: 10.4172/2155-6113.1000691

Page 7 of 7

22. Kim JH, Psevdos Jr G, Gonzalez E, Singh S, Kilayko MC, et al. (2013) Allcause mortality in hospitalized HIV-infected patients at an acute tertiary care hospital with a comprehensive out patient HIV care program in New York City in the era of highly active antiretroviral therapy (HAART). Infection 41: 545-551.

23. Shuper PA, Neuman M, Kanteres F, Baliunas D, Joharchi N, et al. (2010) Causal considerations on alcohol and HIVIAIDS: A systematic review. Alc Alcoholism 45: 159-166.

24. Reddy KP, Parker RA, Losina E, Baggett TP, Paltiel AD, et al. (2016) Impact of cigarette smoking and smoking cessation on life expectancy among people with HIV: A US-based modeling study. J Infect Dis 214: 1672-1681.

25. Kipp AM, Desruisseau AJ, Qian HZ (2011) Non-injection drug use and HIV disease progression in the era of combination antiretroviral therapy. J Subst Abuse Treat 40: 386-396.

26. Barbier F, Coquet I, Legriel S, Pavie J, Darmon M, et al. (2009) Etiologies and outcome of acute respiratory failure in HIV-infected patients. Intens Care Med 35: 1678-1686.

27. Mendez-Tellez PA, Damluji A, Ammerman D, Colantuoni E, Fan E, et al. (2010) Human immunodeficiency virus infection and hospital mortality in acute lung injury patients. Crit Care Med 38: 1530-1535.

28. Mrara B (2015) To initiate or not to initiate antiretroviral therapy in the critically ill? South Afr J Anaesth Analg 21: 62-63.

29. Silva Jr JM, Santos SS (2013) Sepsis in AIDS patients: Clinical, etiological and inflammatory characteristics. J Intern AIDS Soc 16: 17344. 